\title{
Chest wall infarction following bilateral internal mammary harvesting for coronary revascularization in a patient with previous aortic abdominal aneurysm surgery: a rare complication.
}

\author{
Joel Lapeze ${ }^{1}$, Fabien Boucher ${ }^{2}$, and Fadi FARHAT ${ }^{3}$ \\ ${ }^{1}$ Infirmerie Protestante de Lyon \\ ${ }^{2}$ Hopital de la Croix-Rousse \\ ${ }^{3}$ Hopital Cardio-vasculaire et Pneumologique Louis Pradel
}

April 20, 2021

\begin{abstract}
A 75 years old man with previous aortic abdominal aneurysm surgery through a transverse laparotomy underwent bilateral internal mammary artery (BIMA) to coronary artery bypass grafting (CABG). He immediately thereafter developed a severe chest and upper abdominal walls ischemia with metabolic acidosis, and finally deep sternum wound infection and upper abdominal wall necrosis. He benefitted from sternal reconstruction and vaccum assisted treatment, with delayed pectus major flap reconstruction. Chest and abdominal wall infarction following BIMA harvesting is a very rare but life-threatening complication. Caution use of BIMA should be in order in patients with inferior epigastric artery flow impairment.
\end{abstract}

\section{Introduction}

Bilateral internal mammary artery use is widely recognized as a beneficial approach for coronary artery bypass grafting surgery [1-2], in terms of mid- and long-term survival. Chest wall ischemia after BIMA harvesting is an extremely rare complication leading to deep chest wound infection and variable extent of wall necrosis [3].

\section{Case}

We report a 75 years old man case who underwent years ago an abdominal aortic aneurysm surgery through a transverse laparotomy approach. Inferior epigastric arteries were both ligatured during this previous surgery. Recently, this patient underwent an off-pump BIMA to coronary artery bypass, using a skeletonized harvesting technique, with favorable postoperative hemodynamics and cardiac output.

Nevertheless, he immediately developed a severe chest and upper abdominal walls ischemia (Figure 1a). The routine laboratory tests rapidly showed a metabolic acidosis with a minimal $\mathrm{pH}$ at 7.22 and maximal lactate level at 6.1. Maximal postoperative troponin I level was $1.85 \mu \mathrm{mol} / \mathrm{l}$. The patient rapidly developed an acute renal failure with a maximal creatinin level at $338 \mu \mathrm{mol} / \mathrm{l}$. Creatine kinase raised up to $4346 \mathrm{U} / \mathrm{L}$ on POD 5. An abdominal CT-scan didn’t show any digestive ischemia.

Wall necrosis was confirmed by clinical aspect at redo-surgery (Figure 1b) at POD 30. This intervention was motivated by a severe deep sternal wound infection. Microbiological agents involved were Morganella Morgani, Klebsiella Pneumonia BLSE and Enterococcus faecalis, and were treated by meropenem and amikacine for 8 weeks.

First redo surgery consisted in the debridement of necrotic tissues, iterative sternal osteosynthesis using the cabled butterfly sternal closure technique [4], and Vacuum Assisted Closure (V.A.C.) device for the 
upper abdominal defect. Therefore, eight weeks of concomitant V.A.C. and antibiotics therapy permitted to sterilize the wound, to obtain sternal consolidation and to reduce parietal defect (Fig 2a).

Secondary, the patient underwent a right pedicled pectoralis major muscle flap for parietal coverage (Fig $2 \mathrm{~b}$ ). At POD 15 of this third surgery, clinical examination showed sternal stability and satisfying parietal healing.

\section{Conclusion}

Chest and abdominal wall infarction is an extremely rare complication of BIMA harvesting during CABG surgery, leading to deep sternal wound infection and parietal defect. Butterfly sternal closure technique, pectoralis major flap reconstruction and Vacuum Assisted Closure device therapy can be useful in the management of these challenging complications. Although BIMA has proved its benefits in mid- and long-term survival after surgical coronary revascularization, cautions should be in order in patients with compromised inferior epigastric artery flow.

\section{Figures}

Figure 1a Parietal ischemia of the lowr part of the anterior chest wall and the upper abdomena

Figure 1b Parietal defect after debridement and sternal reconstruction

Figure 2a Residual parietal defect after 8 weeks of VAC therapy

Figure 2b Final aspect after pectoralis major flap reconstruction

\section{References}

[1] Weiss AJ, Zhao S, Tian DH, Taggart DP, Yan TD. A meta-analysis comparing bilateral internal mammary artery with left internal mammary artery for coronary artery bypass grafting. Ann Cardiothorac Surg 2013;2:390-400.

[2] Taggart DP, Altman DG, Gray AM, Lees B, Nugara F, Yu LM, Campbell H, Flather M, ART Investigators. Randomized trial to compare bilateral vs. single internal mammary coronary artery bypass grafting: 1-year results of the Arterial Revascularisation Trial (ART). Eur Heart J 2010;31:2470-80.

[3] Keyser EJ, Ergina PL, Melanson PR, de Varennes B. Chest wall infarction following bilateral internal mammary to coronary arterial bypass in a patient with a thoracoabdominal aneurysm. J Card Surg $1997 ; 12: 126-9$.

[4] Jolly S, Flom B, Dyke C. Cabled Butterfly Closure: A Novel Technique for Sternal Closure. Ann Thorac Surg 2012;94:1359-61

\section{Hosted file}

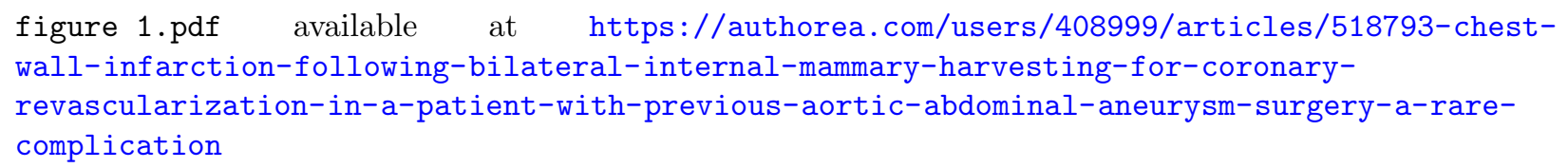

\section{Hosted file}

figure 2.pdf available at https://authorea.com/users/408999/articles/518793-chestwall-infarction-following-bilateral-internal-mammary-harvesting-for-coronaryrevascularization-in-a-patient-with-previous-aortic-abdominal-aneurysm-surgery-a-rarecomplication 